\title{
Prospective 12 month study of 30 minute decision to delivery intervals for "emergency" caesarean section
}

\author{
I Z MacKenzie, Inez Cooke
}

Editorial by James Papers $\mathrm{p} 1330$

Nuffield

Department of

Obstetrics and

Gynaecology,

University of

Oxford, John

Radcliffe Hospital,

Oxford OX3 9DU

I Z MacKenzie

clinical reader in

obstetrics and

gynaecology

Inez Cooke

clinical lecturer in

obstetrics and

gynaecology

Correspondence to: I Z MacKenzie

BMJ 2001;322:1334-5
Clinical governance requires evidence based standards of clinical relevance to assess performance. The recommended interval between the decision to perform an "emergency" caesarean section and the procedure is 30 minutes ${ }^{12}$ but there is little objective evidence to support this recommendation. We conducted a prospective 12 month study in a large consultant obstetric teaching unit to examine whether the time between the decision to perform a caesarean section to actual delivery affects the success of the delivery.

\section{Participants, methods, and results}

Time intervals between a decision to deliver and actual delivery were collected prospectively for all caesarean sections from 1 January 1996 to 31 December 1996. Clinical staff were not aware of the audit since by April 1995 all staff had been required to record these times with the guidelines expecting all deliveries within 30 minutes. Caesarean sections were classified as emergency (decision made during labour because of evolving fetal distress, failing labour, or maternal reasons; 385 deliveries), crash (decision made if impending fetal death or serious maternal compromise anticipatedfor example, cord prolapse, placental abruption, or uterine rupture; 24 deliveries), urgent (decision made during the 24 hours before delivery because of deteriorating fetal or maternal health before the onset of labour; 67 deliveries), pre-empted (decision made more than 24 hours before the onset of spontaneous labour or membrane rupture; 57 deliveries), or elective (decision made more than 24 hours before delivery; 368 deliveries).

Fetal distress was the primary clinical indication for intrapartum section if it was documented in the clinical records; if fetal distress was not documented, it was assumed to be absent. "Distress" during pregnancy was determined using various fetal diagnostic tests.

During the study period babies were delivered to 5846 mothers. Delivery was by caesarean section in $901(15.4 \%)$ cases, with decision times available for $415(77.8 \%)$ of the 533 non-elective deliveries and cord arterial $\mathrm{pH}$ values available for 490 (91.9\%). Maternal age, parity, and gestation were similar for the 159 deliveries with fetal distress and the 374 deliveries without fetal distress.

The figure shows the relation between the intervals from decision to delivery, with and without fetal distress, and the cord arterial $\mathrm{pH}$ values. The time interval with fetal distress (mean 42.9 (SD 24.1) min; median $35 \mathrm{~min}$ ) was significantly shorter than without distress (71.1 (42.3) min; $\mathrm{P}<0.0001$, Student's $t$ test) and showed lower cord arterial $\mathrm{pH}$ values $(7.20(0.09) \mathrm{v}$ 7.24 (0.09); $\mathrm{P}=0.0004)$. Overall, as time between decision and delivery lengthened, there was a trend towards less acidaemia. For all emergency caesarean sections there was a trend towards shorter time intervals for mothers in more advanced labour, but no trend in levels of acidaemia. General anaesthesia rather than regional anaesthesia resulted in shorter time intervals for fetal distress (22.6 (14.6) min $v 50.0$ (23.0) $\min ; \mathrm{P}<0.001)$. The time of day of delivery, the day of the week of delivery, and the seniority of the surgeon were not related to the time interval whether fetal distress was present or not.

\section{Comment}

In 1996, we succeeded in delivering fewer than $50 \%$ of the babies in 30 minutes despite a positive attempt to achieve this; our performance for delivery with fetal distress was similar to that reported from our unit for 1989 (median time 34 minutes). ${ }^{3}$ Possible explanations for this lack of improvement include fewer staff, increased caesarean section workload, increasing use of regional anaesthesia, and reduced experience of obstetric staff.

The trend of improved cord arterial $\mathrm{pH}$ values with more prolonged delivery times with and without fetal

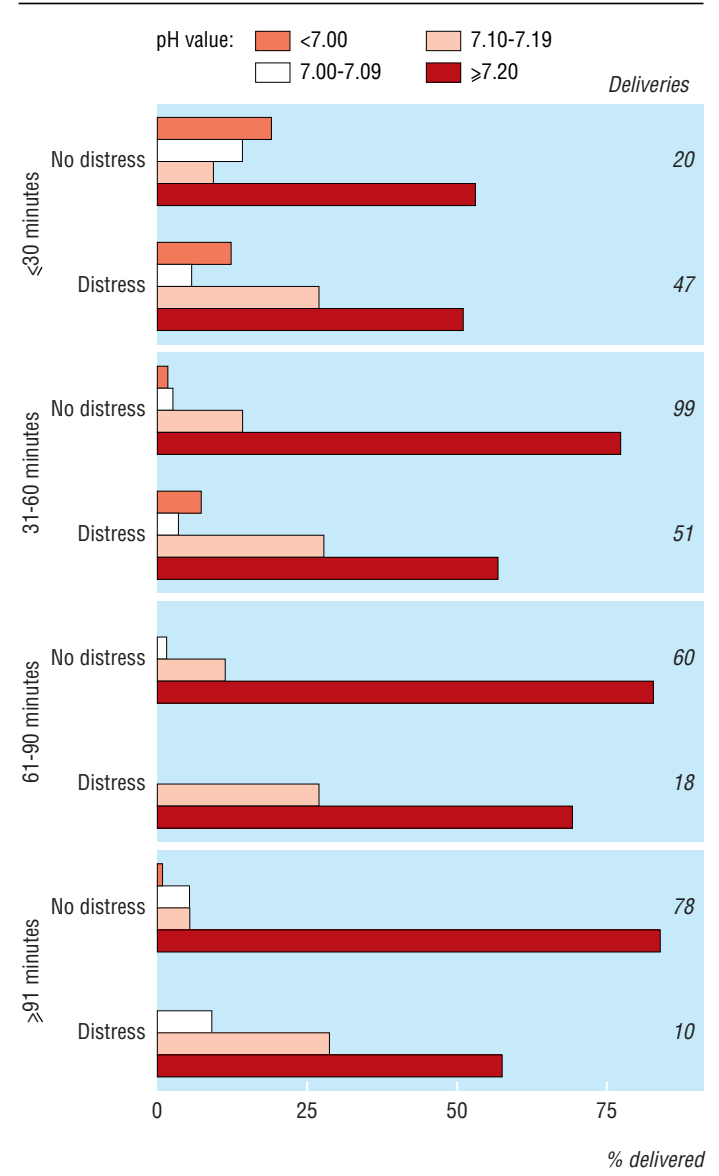

Relation between cord arterial $\mathrm{pH}$ and decision to delivery interval for 126 caesarean sections performed because of fetal distress and 257 performed without fetal distress 
distress is important. It is hard to explain this trend, especially in the case of deliveries without fetal distress, although we found a similar trend with assisted vaginal vertex deliveries for fetal distress. ${ }^{4}$ The anxiety for the patient generated by the decision for caesarean section may provoke increased maternal catecholamine release that initially causes reduced perfusion of the placental bed and gas exchange, with temporary fetal acidosis. Cord $\mathrm{pH}$ values may not be a reliable assessment of fetal or neonatal wellbeing nor a good predictor of long term neurological outcome ${ }^{5}$ but we question the benefit and wisdom of aiming to achieve delivery in all cases within 30 minutes.

We thank Mrs Maggie Jefferies and the maternity records coding staff who provided a crosscheck to confirm complete collection of data.
Contributors: IZM and IC were responsible for the design of the study, collected the clinical data, performed data analyses, and prepared the manuscript. IZM is guarantor for the paper. Funding: None declared.

Competing interests: None declared.

1 Hannah WJ, Baskett TJ, Chance GW, Hamilton EF, Huchcroft S, King JF, et al. Indications for cesarean section: final statement of the panel of the National Consensus Conference on Aspects of Cesarean Birth. Can Med Assoc J 1986;134:1348-52.

2 Confidential Enquiry into Stillbirths and Deaths in Infancy. 7th Annual Report. London: Maternal \& Child Health Research Consortium, 2000:41-52.

3 Dunphy BC, Robinson JN, Sheil OM, Nicholls JSD, Gillmer M. Caesarean section for fetal distress, the interval from decision to delivery, and the relative risk of poor neonatal condition.J Obstet Gynaecol 1991;11:241-4

4 Okunwobi-Smith Y, Cooke IE, MacKenzie IZ. Decision to delivery inter vals for assisted vaginal vertex delivery. Br J Obstet Gynaecol 2000;107: 467-71.

5 Dennis J, Johnson A, Mutch L, Yudkin P, Johnson P. Acid-base status a birth and neurodevelopment outcome at four and one-half years. $A m J$ Obstet Gynecol 1989;161:213-20.

(Accepted 12 March 2001)

\section{Comparison of breastfeeding rates in Scotland in 1990-1 and 1997-8}

David M Tappin, Joan M Mackenzie, Arlene J Brown, Robert W A Girdwood, Jane Britten, Mary Broadfoot

In 1994 the Committee on Medical Aspects of Food Policy recommended that mothers should be encouraged and supported to breast feed for at least four months. ${ }^{1}$ This has been adopted as policy in Scotland, and a target was set by the Scottish Office in 1994: " $50 \%$ still breastfeeding at 6 weeks postnatal age by 2005." ${ }^{2}$ Breastfeeding rates in Scotland reported for 1990-1 used information gathered on inborn errors screening (Guthrie) cards at 7 days' postnatal age and covered $99.8 \%$ of babies. ${ }^{3}$ This paper considers the increase in breastfeeding rates over an eight year period in Scotland to 1997-8, with correction for demographic changes in maternal age, as older women are more likely to choose to breast feed. ${ }^{4}$

\section{Methods and results}

Information on breast feeding, hospital of birth, and health board has been collected on Guthrie cards in
Scotland since the National Inborn Errors Screening Programme was established in 1964. All information is transferred to a computer database in one Glasgow laboratory. Postcode information has been available since 1990 and maternal age since 1995. Since 1990 breastfeeding rates have been reported to maternity units and health boards throughout Scotland.

During 1990-1, 131759 babies were born in Scotland, ${ }^{3}$ and 118055 babies were born in 1997-8 (total births 118647 (Information and Statistics Division Scotland, Common Services Agency, Edinburgh)). The number of infants who were breast fed and the number who were bottle fed were determined for each postcode area (table). Confidence intervals were calculated for the difference in the proportion of breastfed babies between the two periods.

In Scotland, breast feeding at 7 days of age has increased by $6.4 \%$ (95\% confidence interval 6.0 to 6.8$)$ from $35.6 \%$ in $1990-1$ to $42.0 \%$ in $1997-8$. The largest

Numbers (percentages) of babies born in each postcode area of Scotland in 1990-1 and 1997-8 who were breast fed, taken from information recorded on Guthrie cards

\begin{tabular}{|c|c|c|c|}
\hline Postcode area & Breast fed/total 1990-91 & Breast fed/total 1997-98 & Percentage difference $(95 \% \mathrm{Cl})$ \\
\hline EH (Edinburgh*) & $8751 / 22381(39.1)$ & $9557 / 18905(50.6)$ & 11.5 (10 to 12$)$ \\
\hline KW (Kirkwall, Orkney) & $456 / 1044(43.7)$ & $544 / 1010(53.9)$ & $10.2(5.9$ to 14$)$ \\
\hline PH (Perth*) & $1657 / 3486(47.5)$ & $1883 / 3270(57.6)$ & 10.1 (7.7 to 12) \\
\hline KA (Kilmarnock, Ayrshire) & $2911 / 10028(29.0)$ & $3192 / 8510(37.5)$ & 8.5 (7.1 to 9.9$)$ \\
\hline G (Glasgow*) & $8852 / 32476(27.3)$ & 10 291/28 937 (35.6) & $8.3(7.6$ to 9.0$)$ \\
\hline FK (Falkirk*) & $1951 / 6425(30.4)$ & $2249 / 5996(37.5)$ & $7.1(5.4$ to 8.8$)$ \\
\hline PA (Paisley, Renfrewshire) & $2994 / 9096(32.9)$ & $2966 / 7461$ (39.8) & $6.9(5.4$ to 8.4$)$ \\
\hline ML (Motherwell, Lanarkshire) & $1836 / 8719(21.1)$ & $2371 / 8797(27.0)$ & $5.9(4.6$ to 7.2$)$ \\
\hline TD (Galashiels, Selkirkshire) & $864 / 1900(45.5)$ & $951 / 1873(50.8)$ & $5.3(1.1$ to 8.5$)$ \\
\hline DD (Dundee $\left.{ }^{*}\right)$ & $2698 / 6920(39.0)$ & $2754 / 6264(44.0)$ & 5.0 (3.3 to 6.7$)$ \\
\hline IV (Inverness*) & $2660 / 5456(48.8)$ & $2656 / 5029(52.8)$ & $4.0(2.1$ to 5.9$)$ \\
\hline DG (Dumfries $\left.{ }^{\star}\right)$ & 1396/3482 (40.1) & $1369 / 3180(43.1)$ & $3.0(0.6$ to 5.4$)$ \\
\hline KY (Kirkcaldy, Fife) & $3681 / 8654(42.5)$ & $3496 / 7697(45.4)$ & $2.9(1.4$ to 4.4$)$ \\
\hline ZE (Lerwick, Shetland) & $376 / 636(59.1)$ & $301 / 553(54.4)$ & $-4.7(-10.3$ to 0.9$)$ \\
\hline $\mathrm{AB}\left(\right.$ Aberdeen $\left.{ }^{\star}\right)$ & $5866 / 11056(53.1)$ & $5035 / 10573(47.6)$ & $-5.5(-6.8$ to -4.2$)$ \\
\hline All Scotland & 46 949/131 759 (35.6) & 49 615/118 055 (42.0) & $6.4(6.0$ to 6.8$)$ \\
\hline
\end{tabular}

\footnotetext{
*Includes surrounding areas.
}

Paediatric

Epidemiology and Community Health (PEACH) Unit, Department of Child Health, Royal Hospital for Sick Children, Glasgow G3 8SJ

David M Tappin clinical senior lecturer Jane Britten research assistant Mary Broadfoot information officer

Scottish Inborn Errors Screening Laboratory, Stobhill General Hospital, Glasgow G21 3UW Joan M Mackenzie biomedical scientist Arlene J Brown clinical scientist Robert W A

Girdwood

consultant microbiologist

Correspondence to: D M Tappin goda11@udcf.gla. acuk

BMJ 2001;322:1335-6 